\title{
Tingkat Perubahan Garis Pantai Menggunakan Metode Analisis Regresi Linier (Studi kasus di Tanjung Leban)
}

\author{
Sony Adiya Putra \\ Program Studi Teknik Sipil, Sekolah Tinggi Teknologi Dumai, \\ Jl. Utama Karya Bukit Batrem II \\ Email : sonyadiyaputra@yahoo.co.id
}

\begin{abstract}
ABSTRAK
Daerah pesisir adalah daerah yang dinamis, di mana daerah pesisir mengalami proses perubahan terus-menerus dan dapat terjadi setiap saat. Oleh karena itu, dengan kemajuan teknologi dapat diamati melalui tingkat abrasi dan perubahan garis pantai terjadi di Tanjung Leban dengan menggunakan data gambar Landsat 17 tahun terakhir. Tingkat perubahan garis pantai dianalisis dengan regresi linierr digital Shoreline Analysis System (DSAS). Hasil penelitian ini menunjukkan bahwa sebagian besar pantai di desa Tanjung Leban terjadi abrasi dengan berbagai tingkat abrasi. Dalam 17 tahun terakhir telah terjadi abrasi terbesar dengan 11,2 m yang terletak di jalan desa Tanjung Leban di Sungai Gayo yang posisinya jauh di ujung yang juga dekat dengan pantai Jl. Imam barokah. Hal ini mengindikasikan bahwa Tanjung Leban mengalami pengurangan luas lahan. Oleh karena itu disarankan bahwa di pantai kritis mengalami tingkat abrasi maksimum ditangani segera sehingga peristiwa abrasi tidak terus di tahun-tahun berikutnya.
\end{abstract}

Kata kunci: Abrasi, Data Gambar Pendaratan, LRR, DSAS.

\begin{abstract}
The coastal area is a dynamic area, where the coastal areas undergo a process of continuous change and can occur at any time. Therefore, with technological progress, it can be observed how big the abrasion rate and how far the coastline change happened in Tanjung Leban by using the Landsat image data of the last 17 years. The rate of shoreline change analyzed by Linear Regression Rate (LRR) Digital Shoreline Analysis System (DSAS). The results of this study indicate that most of the beaches of Tanjung Leban village occur abrasion with varying abrasion rates. In the last 17 years, there has been the largest abrasion with $11.2 \mathrm{~m}$ located on Street Desa Tanjung Leban on the Sungai Gayo, whose position is at the far end which is also close to the coast of Jl. Imam Barokah. This position indicates that Tanjung leban experienced a substantial reduction in the land area. It recommends that at critical beaches experiencing maximum abrasion rates to be addressed immediately so that the abrasion event does not continue in subsequent years.
\end{abstract}

Keywords: Abrasion, Landing Image Data, LRR, DSAS 


\section{Pendahuluan}

ArcGIS adalah paket perangkat lunak yang terdiri dari produk perangkat lunak Sistem Informasi Geografis (SIG) yang di produksi oleh ESRI. ESRI adalah perusahaan yang bergerak pada bidang perangkat lunak sistem informasi geografis. Saat ini penggunaan data satelit citra penginderaan jauh seperti sistim informasi geografis (GIS) berperan sangat penting sebagai sebuah metode yang murah dan mudah dalam penyediaan data liputan kawasan pesisir dan sekitarnya. Kerusakan pantai dapat diakibatkan oleh faktor baik dari alam maupun manusia. Proses dari alam gerakan angin, arus maupun diakibatkan oleh gelombang yang biasa terjadi nya perubahan garis pantai. Perubahan garis pantai oleh kegiatan manusia antara lain adalah kegiatan pembangunan pelabuhan, pertambangan, penggerukan dan kegiatan wisata pantai (Azhar, 2012). Menurut Bambang Triatmodjo, 1999, terjadinya erosi atau abrasi sebagai akibat dari perubahan bentuk gelombang laut. Fenomena tersebut dapat merusak garis pantai dan mengancam infrastruktur wilayah pesisir pantai yang bisa mengakibatkan pengurangan daratan serta besarnya potensi ancaman bencana.

\section{Metode Penelitian}

Penelitian ini dilakukan di sepanjang pesisir pantai Desa Tanjung Leban kecamatan Bukit Batu, yang berkedudukan ibukota Sungai Pakning, Provinsi Riau yang merupakan daerah berbatasan langsung dengan Selat Malaka Negara Malaysia dan juga sangat dekat dengan Pulau Bengkalis. Tanjung Leban dan sekitarnya merupakan daerah yang memiliki peranan yang sangat penting bagi Kabupaten Bengkalis karena sebagai pusat perikanan, sementara di darat ada perkebunan sawit. Selain itu daerah disekitar Tanjung Leban Kecamatan Bukit Batu ini telah dibangunnya pabrik industri yang seharusnya kita lindungi pesisir pantai agar tidak semakin berkurang akibat dari abrasi tersebut.

Data citra satelit ini merupakan data utama yang dibutuhkan untuk analisis awal pada penelitian ini. Pemilihan jenis produk penginderaan jauh yang akan dipakai pada penelitian ini utamanya dipengaruhi oleh ketersediaan rekaman data di lokasi penelitian pada interval waktu yang relatif cukup panjang. Serta dengan kualitas yang dipilih berdasarkan band-band pada rekaman data historis berdasarkan data Landsat collection level. Data Landsat 4-5 TM dengan resolusi 30 meter tersedia sejak tahun 1982, data Landsat 7 ETM hingga tahun 2012 lalu di ikuti penggunaan Landsat 8 OLI-TIRS sejak tahun 2013 hingga sekarang, maka didapatkan rekaman data selama jangka waktu 17 tahun.

Selain itu pengunaan Arcgis sebagai software nya dalam memproses data tersebut serta DSAS (Digital Shoreline Analysis Sistem) dalam proses perhitungan metode nya penggunaan USGS dalam data raster merupakan data utama yang diperlukan sebelum dikelola. Pengolahan data citra satelit dilakukan dengan menggunakan ArcGIS 10.3 meliputi pemotongan citra untuk membatasi lokasi penelitian, pemulihan citra, penajaman citra, koreksi geometrik, digitasi dan 
pengklasifikasian, dan tumpang susun overlay (Thieler, dkk., 2009) untuk memperoleh informasi garis pantai masing-masing tahun pengamatan. Adapun proses yang akan dilakukan dalam penelitian ini yaitu analisis dan interprestasi data satelit (Landsat) untuk pemetaan perubahan garis pantai dan juga analisis statik pada tingkat perubahan garis pantai selama 17 tahun terakhir.

Sistem informasi Geografis (SIG) adalah sistem informasi yang berfungsi untuk mengelola data yang berupa informasi keruangan (spasial). Dalam bahasa Inggris, SIG disebut Geographic Information system (GIS). Information spasial berupa posisi koordinat suatu objek, luasan wilayah dan panjang garis yang diproyeksi dalam sistem koordinat. Selain informasi spasial, data-data tentang keterangan (atribut) suatu objek, luasan wilayah dan panjang garis merupakan bahan-bahan yang diolah dalam Sistem Informasi Geografis. Aplikasi SIG saat ini mulai banyak digunakan untuk perencanaan, pelaksanaan serta pengendalian yang berkaitan dengan wilayah geografis. Dalam pemanfaatannya, SIG banyak diaplikasikan seperti dijelaskan peruntukan seperti dibawa ini.

a. Pengolahan dan penentuan sumber daya air.

b. Perencanaan umum tata ruang.

c. Mengetahui potensi dan persebaran penduduk.

d. Mengetahui luas dan persebaran lahan pertanian maupun industri lainnya.

e. Untuk pendataan dan pengaturan infrastruktur seperti : kawasan industri, jaringan listrik, telepon, jalan kereta api, bangunan, saluran pipa air minum.

f. Serta informasi wilayah berdasarkan kode pos.

\section{Hasil dan Pembahasan}

Analisis dan pembahasan dilakukan berdasarkan hasil pengujian pengolahan data yang didapat pada penelitian ini menggunakan software ArcGis 10.3 dan aplikasi Digital Shoreline Analysis System (DSAS) sebagai alat bantu pada penelitian ini dilakukan pengumpulan serta penyajian data yang digunakan untuk tahapan analisis. Jenis data satelit yang digunakan dalam penelitian ini data Landsat dengan resolusi menengah, yaitu 30 dan 15 meter. Pemilihan jenis data satelit tersebut didasarkan pada ketersediaan data yang cukup panjang mulai dari tahun 2000 hingga tahun 2017 dengan interval waktu tiap bulan. Spesifikasi data satelit yang digunakan pada penelitian ini seperti disajikan pada Tabel 1.

Tabel 1. Data citra satelit landsat yang digunakan

\begin{tabular}{|c|c|c|c|}
\hline Satelit & $\begin{array}{c}\text { Tahun Pengambilan } \\
\text { Data }\end{array}$ & Jenis Sensor & Resolusi \\
\hline Landsat 4-5 & $24 / 08 / 2000$ & TM & $30 \mathrm{~m}$ \\
\hline Landsat $4-5$ & $19 / 06 / 2005$ & TM & $15 \mathrm{~m}, 30 \mathrm{~m}$ \\
\hline Landsat -7 & $05 / 11 / 2006$ & TM & $30 \mathrm{~m}$ \\
\hline Landsat -7 & $26 / 03 / 2012$ & ETM+ & $15 \mathrm{~m}, 30 \mathrm{~m}$ \\
\hline Landsat -8 & $12 / 08 / 2013$ & OLI_TIRS & $15 \mathrm{~m}$ \\
\hline Landsat -8 & $24 / 09 / 2017$ & OLI_TIRS & $15 \mathrm{~m}$ \\
\hline
\end{tabular}

Sumber : Data Pencatatan Citra Satelit 


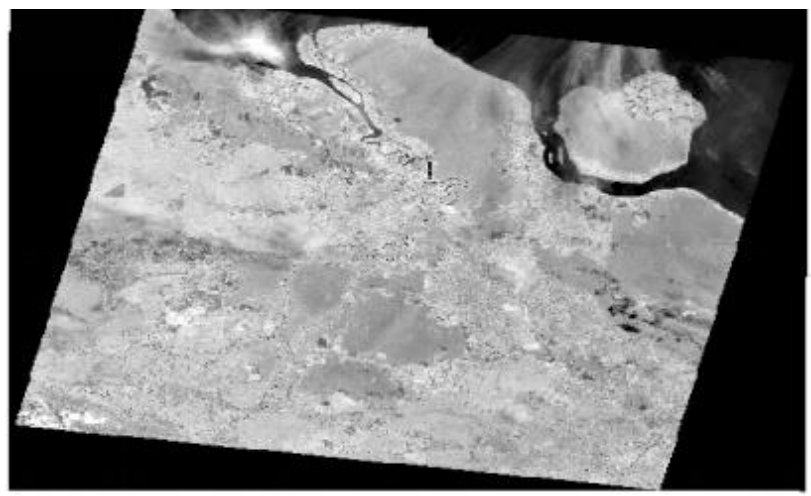

Gambar 1. Tampilan Band 4 Perekaman Tanggal 24 Agustus 2000 Sumber : Citra Landsat 4-5 ETM

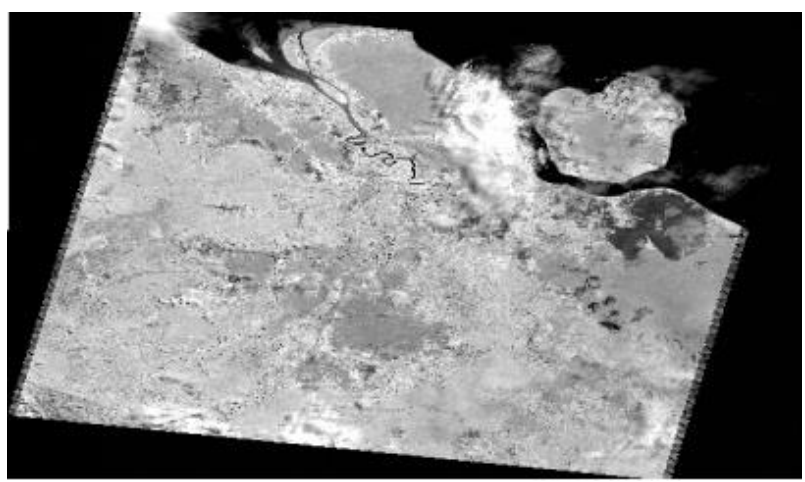

Gambar 2. Tampilan Band 4 Perekaman Tanggal 19 Juni 2005 Sumber : Citra Landsat 4-5 ETM

Tabel 2. Hasil rekapitulasi perubahan garis pantai dengan metode LRR

\begin{tabular}{|c|c|c|c|c|c|c|}
\hline Object Identifier $*$ & TransectId $*$ & TCD & LRR & LR2 & LSE & LCI99_9 \\
\hline 1 & 2 & 50 & -5.39 & 0.9 & 10.33 & 6.414 \\
\hline 2 & 3 & 100 & -5.32 & 0.9 & 10.01 & 6.214 \\
\hline 3 & 4 & 150 & -5.28 & 0.9 & 9.68 & 6.011 \\
\hline 4 & 5 & 200 & -5.23 & 0.9 & 9.44 & 5.863 \\
\hline 5 & 6 & 250 & -5.15 & 0.9 & 9.37 & 5.817 \\
\hline 6 & 7 & 300 & -5.06 & 0.9 & 9.28 & 5.763 \\
\hline 7 & 8 & 350 & -4.97 & 0.9 & 9.21 & 5.719 \\
\hline 8 & 9 & 400 & -4.88 & 0.9 & 9.2 & 5.713 \\
\hline 9 & 10 & 450 & -4.7 & 0.9 & 8.94 & 5.551 \\
\hline 10 & 11 & 500 & -4.21 & 0.9 & 10.2 & 6.334 \\
\hline 11 & 12 & 550 & -3.88 & 0.9 & 11.47 & 7.123 \\
\hline 12 & 13 & 600 & -3.81 & 0.8 & 11.67 & 7.244 \\
\hline 13 & 14 & 650 & -3.86 & 0.9 & 11.44 & 7.104 \\
\hline 14 & 15 & 700 & -3.99 & 0.9 & 11.18 & 6.942 \\
\hline 15 & 16 & 750 & -4.17 & 0.9 & 10.73 & 6.66 \\
\hline 16 & 17 & 800 & -4.2 & 0.9 & 10.94 & 6.793 \\
\hline 17 & 18 & 850 & -4.24 & 0.9 & 11.06 & 6.868 \\
\hline 18 & 19 & 900 & -4.33 & 0.9 & 10.83 & 6.726 \\
\hline 19 & 20 & 950 & -4.64 & 0.9 & 8.95 & 5.557 \\
\hline 20 & 21 & 1000 & -4.77 & 0.9 & 8.15 & 5.059 \\
\hline
\end{tabular}

Sumber : Hasil perhitungan LRR (2017) 
Dari hasil rekapitulasi tabel diatas maka dapat dijelaskan hal-hal berikut ini.

1. Nilai LRR positif (+) maka terjadi akresi atau kemajuan garis pantai kearah laut, sebaliknya nilai LRR negati (-) maka terjadi abrasi atau kemunduran garis pantai kearah darat.

2. Nilai dari LRR adalah meter.

3. Object identifier yaitu menunjukkan titik lokasi yang ditinjau, seperti 1, 2, 3 dan seterusnya berarti titik-titik lokasi yaitu lokasi 1, lokasi 2, lokasi 3 dan seterusnya.

4. Transectld yaitu menunjukkan garis transek, seperti garis transek 1, garis transek 2, garis transek 3 dan seterusnya.

5. TCD yaitu Transect Cast Direction, menunjukkan jarak dari transek 1 ke transek 2 , transek 1 ke transek 3 dan seterusnya.

6. LR2 yaitu $R$-squared menunjukkan tingkat keakuratan perhitungan.

7. LSE yaitu tingkat akurasi kesalahan perhitungan.

8. LCI yaitu interval tingkat akurasi kesalahan perhitungan.

Hasil analisis perubahan garis pantai sepanjang pesisir pantai Tanjung Leban pada STA 0+000-STA - 0+800 dapat dilihat pada gambar $4.20 \mathrm{~s} / \mathrm{d} 4.21$.

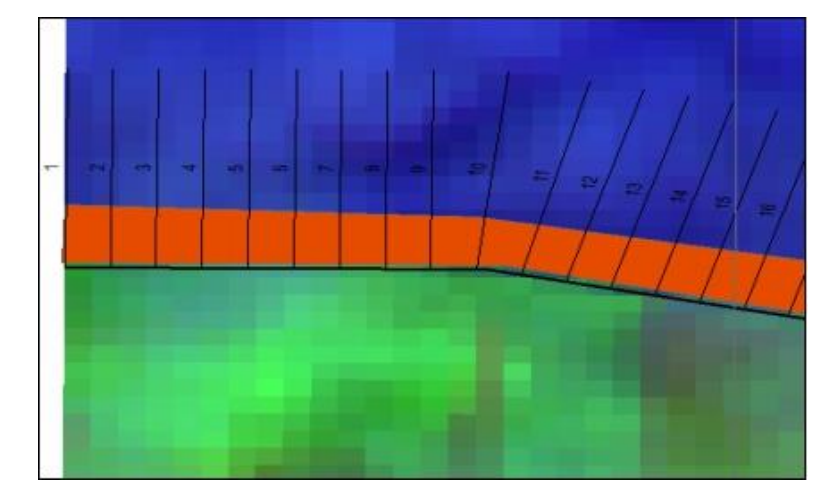

Gambar 3. Titik transek 1-16 (STA 0+000 - STA 0+800)

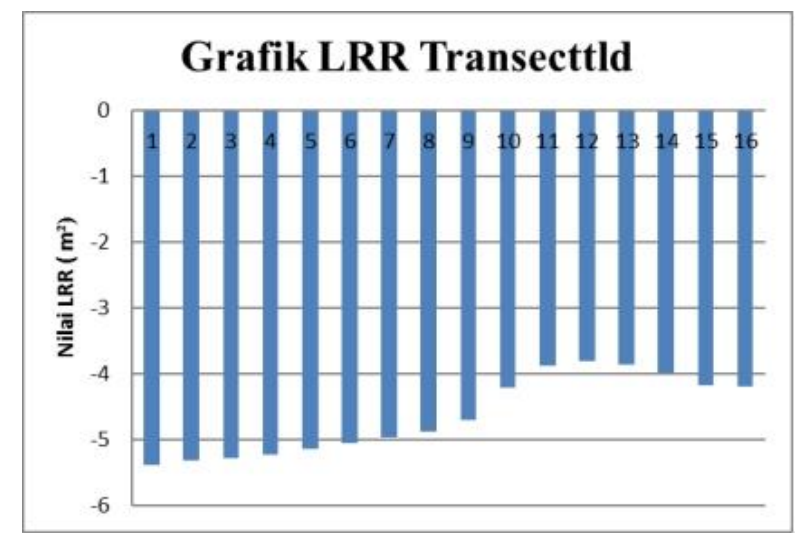

Gambar 4. Grafik Garis Transek LRR 1-16 (STA 0+000 - STA 0+800)

Dari data yang disajikan pada gambar 4.20 dan 4.21 diatas maka menunjukan garis transek yang berada pada STA 0+000 - STA 0+800 dengan nilai tertinggi 
terletak di STA $(0+050)$ pada garis transek yang pertama dengan nilai sebesar -5,39 pada garis transek yang pertama, maka diperoleh nilai LRR yang terjadi pada tahun 2000-2017. Selanjutnya untuk memprediksi besarnya abrasi atau akresi sepanjang pesisir pantai Tanjung Leban 10 tahun kedepan dengan kondisi tanpa pengaman pantai maka dilakukan dengan mengkalikan besarnya LRR pada posisi objek yang ditinjau dengan jarak tahun yang akan ditinjau. Sebagai acuan atau pedoman dimulainya abrasi atau akresi pada tahun pertama pengamatan yaitu Agustus 2000 sampai dengan September 2017. Prediksi besarnya abrasi atau akresi pada tahun 2027 (jangka waktu 2017-2027 adalah 10 tahun) maka besarnya abrasi atau akresi yaitu laju perubahan garis pantai dengan metode LRR pada tahun 2017 yang akan dikalikan dengan jarak tahun yaitu 10 tahun seperti ditunjukkan pada Tabel 3.

Tabel 3. Prediksi besarnya abrasi dan akresi pada tahun 2027

\begin{tabular}{|c|c|c|c|c|c|c|c|}
\hline $\begin{array}{c}\text { object } \\
\text { identifier * }\end{array}$ & TransectId * & TCD & LRR & LRR & $\begin{array}{c}\text { Jangka } \\
\text { Waktu } \\
2017-2027\end{array}$ & $\begin{array}{c}\text { Prediksi } \\
\text { Abrasi Tahun } \\
2027\end{array}$ & Keterangan \\
\hline & & & & $\begin{array}{c}1 \\
\text { Tahun }\end{array}$ & (10 Tahun) & LRR & \\
\hline 1 & 2 & 50 & -5.39 & -0.3171 & 10 & -3.170588235 & Abrasi \\
\hline 2 & 3 & 100 & -5.32 & -0.3129 & 10 & -3.129411765 & Abrasi \\
\hline 3 & 4 & 150 & -5.28 & -0.3106 & 10 & -3.105882353 & Abrasi \\
\hline 4 & 5 & 200 & -5.23 & -0.3076 & 10 & -3.076470588 & Abrasi \\
\hline 5 & 6 & 250 & -5.15 & -0.3029 & 10 & -3.029411765 & Abrasi \\
\hline 6 & 7 & 300 & -5.06 & -0.2976 & 10 & -2.976470588 & Abrasi \\
\hline 7 & 8 & 350 & -4.97 & -0.2924 & 10 & -2.923529412 & Abrasi \\
\hline 8 & 9 & 400 & -4.88 & -0.2871 & 10 & -2.870588235 & Abrasi \\
\hline 9 & 10 & 450 & -4.70 & -0.2765 & 10 & -2.764705882 & Abrasi \\
\hline 10 & 11 & 500 & -4.21 & -0.2476 & 10 & -2.476470588 & Abrasi \\
\hline 11 & 12 & 550 & -3.88 & -0.2282 & 10 & -2.282352941 & Abrasi \\
\hline 12 & 13 & 600 & -3.81 & -0.2241 & 10 & -2.241176471 & Abrasi \\
\hline 13 & 14 & 650 & -3.86 & -0.2271 & 10 & -2.270588235 & Abrasi \\
\hline 14 & 15 & 700 & -3.99 & -0.2347 & 10 & -2.347058824 & Abrasi \\
\hline 15 & 16 & 750 & -4.17 & -0.2453 & 10 & -2.452941176 & Abrasi \\
\hline
\end{tabular}

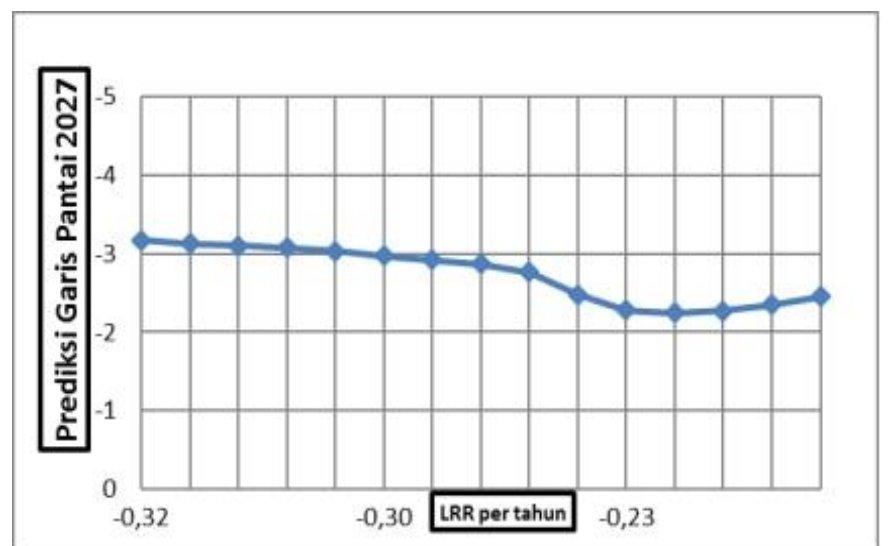

Gambar 5. Grafik Perbandingan Nilai LRR Tahun 2017-2027

UNITEX Vol 12 No.2 Juli-Desember 2019

| p-ISSN 2089-3957 | e-ISSN 2580-2585 


\section{Simpulan}

Dari hasil analisis perubahan garis pantai yang terjadi di sepanjang pesisir pantai Tanjung Leban, maka dapat disimpulkan hal-hal seperti berikut ini :

1. ArcGis digunakan secara luas karena memberikan keuntungan dan nilai tambah jika dibandingkan dengan menggunakan sistem pemetaan manual dan dengan seiringnya perkembangan internet GIS dapat dengan mudah di share melalui internet.

2. Kecamatan Bukit Batu Kabupaten Bengkalis, dari daerah Tanjung Leban hingga sungai Pakning pada daerah Tanjung Leban terjadi pengurangan daratan terbesar karena sama sekali tidak memiliki pengaman pantai.

3. Perubahan garis pantai pada Desa Tanjung Leban dari tahun 2000 hingga 2017 daratan semakin berkurang dan dianalisis dengan menggunakan data Citra Landsat tahun perekaman 24082000 sampai dengan 2409 2017, diperoleh panjang pesisir pantai Tanjung Leban yaitu sekitar $8287.50 \mathrm{~m}$ dan $8278.37 \mathrm{~m}$.

4. Hasil analisis laju perubahan garis pantai Tanjung Leban dengan menggunakan metode Linear Regression Rate (LRR) selama 17 tahun diperoleh laju abrasi terbesar yaitu 11,2 m pada transek 148 yang berada di Desa Sungai Gayo, tingkat keakuratan perhitungan laju abrasi (LR2) yaitu 0.8 dan tingkat kesalahan perhitungan (LSE) yaitu $39,33 \%$. Sementara itu untuk laju akresi tidak terjadi sama sekali.

5. Diprediksi pada tahun 2017-2027 kedepan akan terjadi abrasi atau daratan amblas kelaut yang terbesar yaitu di Desa Sungai Gayo pada (transek 148) sebesar $6.59 \mathrm{~m}$ dengan menggunakan metode LRR. Laju abrasi pertahun nya $0,659 \mathrm{~m}$.

\section{Daftar Pustaka}

C. (2006). A multisource approach for coastline mapping and identification of shoreline changes. Annalys of Geophys, 49 (1), 295-304.

Guariglia A, Arcangela B, Angela L, Rocco S, Maria LT, Angelo Z, Antonio.

Kasim, F. (2012). Pendekatan Beberapa Metode dalam Monitoring.

King, C.A. (1974). Coasts In Geomorphology in Environmental Management an Introduction. Clarendon Pres. Oxford.

Kurnia, A. (2010). Regresi Linier. Artikel Analisa Regresi.

Lillesand, T.M., \& Kiefer, R.W. (1994). Penginderaan Jauh Dan Interpretasi CitraSecond Edition. New York. 
Lindgren D.T. (1985). Land Use Planning and Remote Sensing. Martinus Nijhoff Publishers, Doldrecht. Modeling. The Ohio State University-Press. Ohio.

Mempertajamkan resolusi citra Landsat,online di http://www.infogeospasial.com/2015/07/mempertajamkan-resolusi-citra-landsat-8.html. diakses pada tanggal 20 Agustus 2017.

Mengenal Arcscene dan Arcglobe, online di http://www.majalahbatu.com/2016/08/mengenal-arcscene-dan-arcglobe.html diakses pada tanggal 25 Agustus 2017.

Merubah Data Raster ke Vector di ArcGis, online di http://www.gispedia.com/2016/03/merubah-raster-ke-vektor-di-arcgis.html.diakses pada tanggal 12 Agustus 2017.

Proses Pemotongan Citra, online di http://gaptekgis.blogspot.co.id/2017/01/pemotongan-citra-extraction.html diakses pada tanggal 10 Agustus 2017.

Perubahan Garis Pantai Menggunakan Dataset Penginderaan Jauh Landsat dan SIG. Jurnal Ilmiah Agropolitan, 5(1).

Pratikto, W.A, Armono H.D, \& Suntoyo. (1997). Perencanaan Fasilitas Pantai dan Laut. Edisi Pertama. BPFE. Yoyakarta.

Srivasta, A. (2005), A Least-Squares Approach To Improved Shoreline.

Subaryono. (2005). Pengantar Sistem Informasi Geografis. Jurusan Teknik Geodesi, FT UGM: Yogyakarta.

Sutanto. (1987). Penginderaan Jauh Jilid 2. Yogyakarta : Gadjah Mada University Press.

Thieler ER., \& Danforth WW. (1994). A. Historical shoreline mapping (1) Improving techniques and reducing positioning errors. Journal of Coastal Research, 10, 549-563.

Thieler ER., \& Danforth WW. (1994). B. Historical shoreline mapping (II) Application of the Digital Shoreline Mapping and Analysis Systems (DSMS/DSAS) to shoreline change mapping in Puerto Rico. Journal of Coastal Research, 10(3), 600-620.

Thieler., E.R, Himmelstoss E.A., Zichichi J.L., \& Ergul A. (2009). The Digital Shoreline Analysis System (DSAS) Version 4.0-An ArcGIS Extension for Calculating Shoreline Change. Open-File Report. US Geological Survey Report No. 2008-1278.

Triatmodjo, B. (1999). Teknik Pantai. Yogyakarta: Beta Offset. 
Yuwono. (2005). Teknik Pantai. Yogyakarta: Biro Penerbit Keluarga Mahasiswa Teknik Sipil Fakultas Teknik UGM. 